\title{
PARAPHARYNGEAL SCHWANNOMA ARISING FROM LINGUAL NERVE - A RARE CASE REPORT
}

Krishna Chandra Mallik, Ranjan Kumar Guru, Nilamadhaba Prusty

1. Associate Professor. Department of ENT \& Head Neck Surgery, V.S.S. Medical College, Burla, Odisha.

2. Senior Resident. Department of ENT, V.S.S. Medical College, Burla, Odisha.

3. Post Graduate Student. Department of ENT, V.S.S. Medical College, Burla, Odisha.

\section{CORRESPONDING AUTHOR:}

Dr. Nilamadhaba Prusty,

Room No-217, Post-graduate hostel,

VSS Medical College, Burla,

Sambalpur, Odisha, 768017.

E-mail: nilamadhabprusty@gmail.com

Ph: 00919439482526

ABSTRACT: Parapharyngeal space tumours account for some $0.5 \%$ of tumours of the head and neck. Most of them are benign. The importance of these tumours lies mainly in two aspects: on one hand, the difficulty of early diagnosis, due to the lack of symptoms in the initial stages and, on the other, the extreme complications of performing surgery in the parapharyngeal region. Tumors originating in the parapharyngeal space are rare and are fascinating to the surgeon in view of the anatomical complexity of the area, varied histological types and the impressive size which some of these tumors attain before becoming clinically evident. We report a rare case of schwannoma arising from the lingual nerve \& presenting as a mass in the parapharyngeal space. KEYWORDS: Schwannoma, Parapharyngeal schwannoma, Parapharyngeal tumor.

INTRODUCTION: Parapharyngeal space tumors are rare and account for $0.5 \%$ of all head and neck cancers ${ }^{1}$. Among the parapharyngeal space [PPS] tumors approximately $50 \%$ are salivary gland in origin and $20 \%$ are neurogenic ${ }^{2}$. The most common neurogenic tumor found in the parapharyngeal space is schwannoma ${ }^{2}$. We report a rare case of schwannoma arising from the lingual nerve, presenting as a mass in the parapharyngeal space. The PPS is in the shape of an inverted pyramid, going from the base of the skull to the hyoid bone, up to the petrotympanic part of the temporal lobe. The back wall is delineated by the aponeurosis and the C1, C2 and C3 prevertebral muscles. It is delimited medially by the pharyngobasilar fascia and the superior pharyngeal constrictor muscle, and laterally by the ascending branch of the jaw, superficial cervical aponeurosis and the submaxillary gland. The styloid diaphragm, an aponeurotic sheath originating in the styloid apophysis is located on a plane inclined from above to below and from back to front, dividing the PPS into two compartments: the pre-styloid compartment occupied mainly by the parotid gland deep lobe, and the post-styloid compartment, containing the internal carotid artery, internal jugular vein, cervical sympathetic chain and the last four pairs of cranial nerves ${ }^{3}$.

PPS tumours may remain undetected for long periods of time, and generally present anodyne symptoms, normally as asymptomatic lumps medially displacing oropharyngeal structures. Other symptoms observed include the feeling of having a foreign body, obstruction of tubes, changes in the voice and cervical mass. Pain along with lock-jaw and/or paralysis of any of the pairs of cranial nerves would suggest malignancy ${ }^{4}$. 
Because of its anatomical complexity, complementary MRI and CT scanning are necessary for diagnosis, and Fine Needle Aspiration Cytology (FNAC) is very specific in the histological diagnosis of these tumours. Open biopsy is not advised, due to the risk of bleeding, opening of the capsule and, accordingly, relapse and seeding to neighbouring tissues 5 .

CASE REPORT: A 50 year old male presented with complaints of progressive right side neck swelling since last 2 years. There was no history of any hoarseness, nasal regurgitation, sore throat, otalgia or weight loss. Examination revealed a visible bulge of the right side neck (Fig. 1). Neck examination showed a diffuse bulge below angle of right mandible. There were no palpable neck nodes. Indirect laryngoscopy showed a bulge of right lateral pharyngeal wall with epiglottis being pushed slightly to the left. However both vocal cords were mobile. Cranial nerve examination was normal. A provisional diagnosis of Right parapharyngeal mass was made. Contrast enhanced CT scan of the neck showed a $7 \mathrm{~cm} \times 5 \mathrm{~cm} \times 4.6 \mathrm{~cm}$ size circumscribed mass occupying right parapharyngeal space with peripheral rim enhancement (Fig. 2). There was no involvement of neck vessels and there were no neck nodes. FNAC of the mass was suggestive of a schwannoma. Patient was taken up for excision of the mass through a transcervical approach. Common facial vein and facial artery were ligated and submandibular gland retracted up. Right sternocleidomastoid was retracted and carotid sheath was opened. The tumor was found to be arising from the right lingual nerve. The common carotid artery \& internal jugular vein was found displaced anterolaterally and right vagus was found to be intact. The tumor was found to be well encapsulated and by blunt dissection the superior and inferior aspect of the tumor was identified and the tumor was excised (Fig. 3) along with an intervening segment of the nerve. Post operative period was uneventful \& patient was asymptomatic. Grossly the excised tumor measured $7 \mathrm{~cm} \times 5 \mathrm{~cm} \times 3.5 \mathrm{~cm}$ [Fig. 4]. Microscopic sections of the tumor areas revealed sheets of spindle shaped cells (nerve cells) which were at places forming palisaded nuclei (Verocay bodies). Both cellular (Antoni A) and hypocellular, loose and degenerative (Antoni B) areas were seen.

Final histological report was of a schwannoma.

DISCUSSION: Except olfactory and optic, any nerve can give rise to schwannoma ${ }^{6,7}$. They arise most commonly from the parapharyngeal space in the head and neck region ${ }^{6}$. Most parapharyngeal neurogenic tumors are schwannomas arising from the vagus and less commonly from the sympathetic chain or hypoglossal ${ }^{8}$. Majority of schwannomas are asymptomatic at time of presentation and may have non specific symptoms such as dysphagia or sore throat. The presentation is by exerting pressure on the surrounding structures. Expansion of tumor occurs in the plane of least resistance medially towards the tonsil and lateral pharyngeal wall and posteriorly into retromandibular area presenting as a medial displacement of tonsil, soft palate and pharynx or presenting as a mass near angle of mandible ${ }^{1,2}$. Obstructive symptoms and loss of nerve function may occur as the tumor grows ${ }^{1,2}$.

Schwann cell is the parent cell of both schwannoma and neurofibroma. Neurofibroma also has an origin from the perineurium and is thus linked inseparably from the nerve of origin ${ }^{8}$ and cannot be separated from it. Schwannomas grow longitudinally along the length of the nerve assuming a fusiform appearance without compromising the morphological and functional integrity of the nerve and can be separated surgically from their nerve of origin. Distinction between schwannoma and neurofibroma can be made only microscopically. 
Distinguishing cervical schwannoma from other pathology like salivary gland tumors and paragangliomas in the parapharyngeal space is important. The differential diagnosis of a parapharyngeal mass is based on the division of the space into prestyloid and poststyloid compartments ${ }^{6}$. Contrast enhanced CT scan is the best initial diagnostic study to determine the size and extent of tumor, possible origin of tumor based on displacement of carotid sheath and preservation of parapharyngeal fat and to demonstrate degree of tumor vascularity. CT scan also helps plan the surgical approach and to counsel patient preoperatively about postoperative neurological deficiency. FNAC has revolutionized the ability of clinician to diagnose masses present in the head and neck area. However ability of FNAC to reveal diagnosis is poorly defined in neurogenic tumors ${ }^{9}$. In neurogenic tumors ${ }^{7}$ FNAC was found to give an accuracy of only $25 \%$. as showed in their study by Colreavy et al.

Transcervical, transmandibular and transparotid are the main approaches described ${ }^{1}$ to approach the parapharyngeal space. Schwannomas being well encapsulated tumors can be completely removed during surgery. Selection of the approach to the parapharyngeal space is based on the site and size of the tumor keeping in mind adequate exposure of the tumor and exposure of the neurovascular structures in the vicinity to preserve their function and control bleeding ${ }^{1,2}$. In a study by Mark et $\mathrm{al}^{10}$, out of 4 cases of schwannoma arising from cervical sympathetic the nerve could not be dissected free from the tumor and had to be sacrificed. In our case the lingual nerve could not be dissected free from the tumor and a segment of nerve was sacrificed. Fortunately the post operative period was uneventful.

\section{ABBREVIATIONS:-}

1. PPS - parapharyngeal space.

2. FNAC - Fine needle aspiration cytology.

\section{REFERENCES:-}

1. Pang KP, Goh CHK, Tan HM. Parapharyngeal tumors: an 18 yr review. J Laryngol Otol. 2002;116:170-175. [PubMed]

2. Olsen KD. Tumors and surgery of the parapharyngeal space. Laryngoscope. 1994;104:128. doi: 10.1288/00005537-199405000-00001. [PubMed] [Cross Ref].

3. Rouviére H, Delmas A. Anatomía topográfica de la cabeza y el cuello.En: Anatomía Humana descriptiva, funcional y topográfica. Barcelona:Editorial Masson ; 1987.p.550-6.

4. Rodríguez-Ciurana J, Rodado C, Sáez M, Bassas C. Giant parotid pleomorphic adenoma involving the parapharyngeal space: report of a case. J Oral Maxillofac Surg. 2000 Oct;58(10):1184-7

5. Acosta L, Montalvão P, Magalhães M, Olias J, Santiago N. Parapharyngeal space tumors. Our experience. I.P.O. Francisco Gentil, Lisbon.Acta Otorrinolaringol Esp. 2002 AugSep;53(7):485-90.

6. Mikaelian DO, Holmes WF, Simonian SK. Parapharyngeal schwannomas. Otolaryngol Head Neck Surg. 1981;89:77-81. [PubMed]

7. Colreavy MP, Lacy PD, Hughes J, Bouchier-Hayes D, Brennan P, O’Dwyer AJ. Head and neck schwannomas a 10 yr review. J Laryngol Otol. 2000;114:119-124. doi: 10.1258/0022215001905058. [PubMed] [Cross Ref].

8. Watkinson JC, Gaze MN, Wilson JA (2000) Benign neck disease. In: Stell and Maran's head and neck surgery, 4th edn. Butterworth Heinemann, Oxford, pp 193-194.

9. Ganesan S, Harar RPS, Owen RA, et al. Horner's syndrome: a rare presentation of 
cervical sympathetic chain schwannoma. J Laryngol Otol. 1997;111:493-495. [PubMed].

10. Mark KW, Samuel SG, Robinson JL, Weissmann JL. Cervical sympathetic chain schwannoma. Laryngoscope. 2004;114(12):2210-2213. doi: 10.1097/01.mlg.0000149460.98629.42. [PubMed] [Cross Ref]

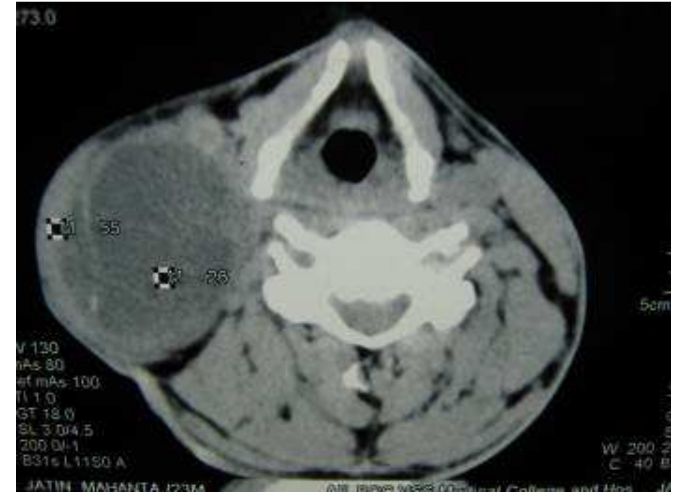

Axial section of neck showing the mass (CT SCAN)

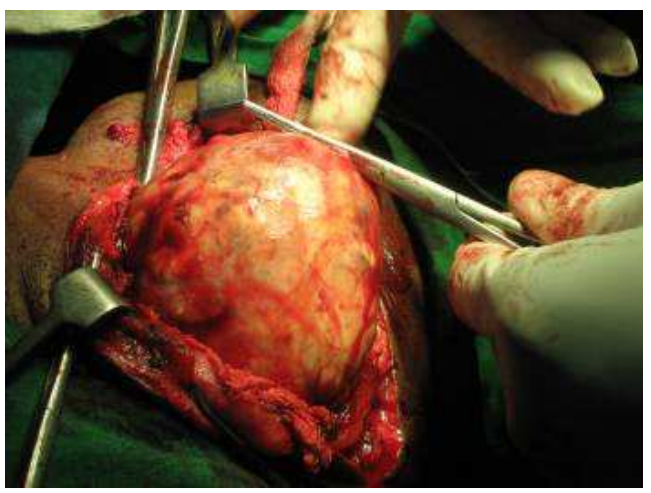

Mass in situ

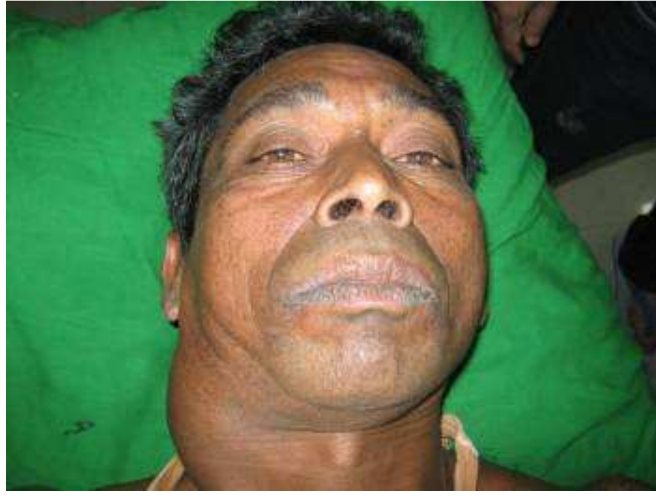

Right side neck mass

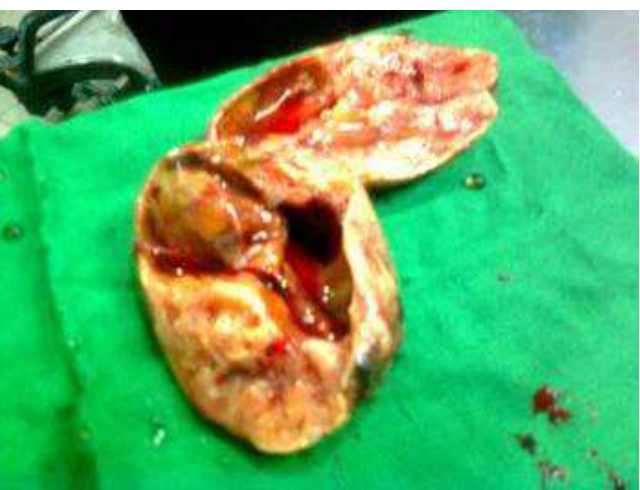

Mass after removal 